\title{
Clinical information has low sensitivity for post mortem diagnosis of heart valve disease
}

Sean Coffey ${ }^{1,2}$, Andrew R Harper ${ }^{1,3}$, Benjamin J Cairns ${ }^{4,5}$, Ian SD Roberts ${ }^{6}$, Bernard D Prendergast ${ }^{7}$

1. National Institute for Health Research (NIHR) Oxford Biomedical Research Centre, Oxford University Hospitals NHS Trust, Oxford, UK

2. Kolling Institute of Medical Research, University of Sydney, Royal North Shore Hospital, St Leonards, Australia.

3. Royal Brompton and Harefield NHS Foundation Trust, London, UK and Wellcome Trust Centre for Human Genetics, University of Oxford, Oxford, UK

4. Cancer Epidemiology Unit, University of Oxford, Richard Doll Building, Roosevelt Drive, Oxford, UK

5. British Heart Foundation Centre of Research Excellence, University of Oxford, Oxford, UK

6. Department of Cellular Pathology, Oxford University Hospitals NHS Trust, Oxford, UK

7. Department of Cardiology, St Thomas' Hospital, London, UK

Key words:- valvular heart disease, autopsy, epidemiology, mortality, death certificates

Corresponding author: Professor Bernard D Prendergast, Department of Cardiology, St Thomas' Hospital, London SE1 7EH, UK

Email: bernard.prendergast@gstt.nhs.uk

Telephone: +44 2071887188 


\section{Abstract}

\section{Background}

Accuracy of routinely collected information concerning cause of death is essential for public health and health systems planning. Since clinical examination has relatively low sensitivity for detection of valvular heart disease (VHD), mortality data based on clinical information alone might routinely underestimate the number of deaths due to VHD.

\section{Methods}

We compared autopsy findings against pre-mortem clinical information for 8,198 consecutive adult post-mortems (mean age 69.1 years, $61.3 \%$ men), performed in a single UK tertiary referral centre with on-site cardiac surgical facilities over a ten-year period (2004-2013) during which $21 \%$ of the adult population underwent post-mortem examination.

\section{Results}

Following post-mortem, VHD was the principal cause of death in 165 individuals (2.0\%), a principal or contributory cause ("any cause") of death in $326(4.0 \%)$ and an incidental (i.e. non-causal) finding in a further $346(4.2 \%)$. Clinical documentation of VHD before death was highly specific but relatively insensitive for post-mortem identification of VHD as the principal (specificity 96.8\%; 95\% Cl: 96.4-97.2; sensitivity $69.7 \%$, 95\% Cl: 62.1-76.6) or any (specificity 98.1\%; 95\% Cl: 97.8-98.4; sensitivity 68.4\%, 95\% Cl 63.1-73.4\%) cause of death. VHD (principally aortic stenosis, endocarditis and rheumatic heart disease) was newly noted at post mortem and listed as a cause of death in 142 individuals (1.7\%). 


\section{Conclusions}

Clinical information recorded pre-mortem is highly specific but relatively insensitive for the cause of death established at autopsy. Population-based mortality statistics that depend upon pre-mortem clinical information are likely to routinely underestimate the mortality burden of VHD. 


\section{Key Questions}

What is already known about this subject?

Data describing the accuracy of death certification for valvular heart disease (VHD) are limited.

\section{What does this study add?}

Clinical information recorded prior to death has high specificity and high positive and negative predictive values, but relatively low sensitivity, for determining VHD as a cause of death. Undiagnosed VHD contributed to death in $1.7 \%$ of the total population; aortic stenosis, infective endocarditis and rheumatic heart disease were the most common causes.

\section{How might this impact on clinical practice?}

Clinicians can be reassured that clinical information recorded pre-mortem accurately determines VHD as a cause of death in individual subjects. However, mortality statistics are likely to significantly underestimate the population prevalence and impact of VHD. 


\section{INTRODUCTION}

Population estimates of the mortality and morbidity burden of specific diseases are acquired from routinely collected information resources, including hospital admission and death certification data. Accurate information concerning cause of death is therefore essential to drive improvements in public health and a key tool in health systems planning. However, these data have well described limitations,[1] and validation of their accuracy in specific situations is essential.[2]

Valvular heart disease (VHD) accounts for significant mortality and morbidity and its prevalence is projected to rise steeply in coming decades as a consequence of the ageing population.[3-5] While early studies found little benefit of screening for VHD in asymptomatic populations, some current guidelines advocate identification of patients at risk of VHD and regular surveillance of asymptomatic subjects in the setting of specialist valve clinics.[6] Early surgery is frequently recommended in asymptomatic severe mitral regurgitation and there is a growing argument for a similar approach in asymptomatic aortic stenosis.[6,7] Estimating the degree of undiagnosed VHD leading to death affords the opportunity for re-evaluation of the role of population-based screening.

Since physical examination has modest sensitivity for the detection of VHD,[8] we hypothesised that cause of death data based solely on clinical information recorded pre-mortem would routinely underestimate the number of deaths related to VHD. Previous studies assessing the correlation between clinical diagnosis of VHD and post-mortem findings have been small and inconclusive. $[9,10]$ We therefore compared pre-mortem clinical information with autopsy findings using the large post-mortem database of a single tertiary referral centre with on-site cardiac surgical facilities over a 10 year period. 


\section{METHODS}

\section{Source of data}

We examined an electronic database containing the reports of consecutive post-mortems performed on adults ( $\geq 18$ years of age) within the Department of Pathology at the John Radcliffe Hospital (Oxford University Hospitals National Health Service [NHS] Foundation Trust) between $1^{\text {st }}$ January 2004 and $31^{\text {st }}$ December 2013. The Trust provides tertiary cardiology and cardiac surgery services to a population of 2.2 million (750 cardiac surgical procedures per annum - 35\% valve surgery, $1.4 \%$ active endocarditis) and secondary hospital services (including pathology) to a local population of 800,000 . Over the time period of this study, $21 \%$ of the deaths in England and Wales were referred for coroner's post-mortem.[11] Registered pathologists who are fellows of the UK Royal College of Pathologists perform all postmortems. Database reports for individual patients were searched electronically for mention of VHD and all reports suggesting its presence reviewed by hand. The study was approved by the Oxford University Hospitals NHS Foundation Trust Audit Committee.

\section{Data extraction}

Each post-mortem report contained basic demographic data and clinical information (recorded in free-text) concerning pre-mortem diagnoses derived from a variety of sources including medical records, Coroner's office reports, and discussion with the treating clinician. We identified VHD as a principal or contributory cause of death and, since most autopsies were performed to resolve uncertainty concerning the cause of death, any other mention of VHD. Local guidance for death certification follows coding recommendations of the World Health Organisation (WHO) using the International Statistical Classification of Diseases and Related Health Problems (Tenth Revision, ICD10).[12] Relevant information is divided into two sections: Part I conditions directly leading to death, and Part II - conditions contributing to (but not directly causing) death. Although there are a number of exceptions, the 
condition appearing on the lowest line of Part I is generally recorded as the principal cause of death.

In the present study, we recorded the cause of death following ICD10 guidelines and defined associations with VHD as follows: (1) VHD as the principal cause of death; (2) VHD as a primary or contributory cause of death (i.e. listed anywhere within Part I or Part II, referred to as "any cause", "any mention", or "multiple-cause-coded" mortality"); and (3) VHD as an incidental finding (noted at autopsy but not recorded on the death certificate).

\section{Statistical analysis}

Our primary analyses measured the sensitivity and specificity of pre-mortem diagnosis for VHD as a principal or contributory cause of death. We present descriptive statistics for prevalence of pre- and post-mortem findings according to age, performance of a medical procedure within 30 days of death, and previously undiagnosed VHD. All statistical analyses were performed using Stata/SE v12.1 (StataCorp, College Station, USA).

\section{RESULTS}

8,198 consecutive post-mortems were performed on adults within the Oxford University Hospitals NHS Foundation Trust between $1^{\text {st }}$ January 2004 and $31^{\text {st }}$ December 2013. Complete data regarding age, gender and reported VHD were available for 7,879 individuals (Table 1).

The overall prevalence of VHD as an identified cause of death increased with age (Figure 1). VHD had been diagnosed in $372(4.5 \%)$ individuals premortem, but was found (as a causal or an incidental finding) in $672(8.2 \%)$ of the total population at autopsy, and in $567(10.1 \%)$ of those aged 65 years and older. VHD was listed as the principal cause of death in 165 individuals (2.0\% of the total population), and as a principal or contributory cause of 
death in $326(4.0 \%)$ (Table 2). Coronary artery disease was the most common principal cause of death when VHD was listed as a contributory cause (Supplementary Table 1).

VHD was listed as a cause of death in 142 individuals (1.7\% of the total population) for whom it had not been documented pre-mortem. The most frequent diagnoses were aortic stenosis ( $n=75,0.9 \%$ of the total population), endocarditis $(n=16,0.2 \%)$, rheumatic heart disease $(n=15,0.2 \%)$, mitral valve disease $(n=9,0.1 \%)$, and bicuspid aortic valve $(n=8,0.1 \%)$. The prevalence of newly noted VHD increased with age (Figure 2).

\section{Sensitivity and specificity}

Pre-mortem clinical information predicted VHD as the principal cause of death with a sensitivity of $69.7 \%(95 \% \mathrm{Cl}: 62.1$ - 76.6) and specificity of $96.8 \%(95 \%$ Cl: 96.4 - 97.2), with no significant difference according to gender (Supplementary Table 2). We observed similar findings for VHD as any cause of death (sensitivity $68.4 \%, 95 \% \mathrm{Cl} 63.1-73.4$; specificity $98.1 \%$; $95 \% \mathrm{Cl}$ : 97.8-98.4) implying that VHD deaths are likely to be underestimated (low sensitivity of pre-mortem information) and unlikely to be overestimated (high specificity of pre-mortem information) at population level.

Excluding valve repair or replacement (both of which are readily determined from the clinical history), analysis according to valve lesion demonstrated a similar pattern of low sensitivity and high specificity in predicting VHD as a principal or contributory cause of death (Supplementary Table 3). Moreover, with the exception of valvular regurgitation, positive and negative predictive values for the pre-mortem diagnosis of specific valve lesions were high (Supplementary Table 3), implying high accuracy of clinical information at individual patient level.

\section{Incidental and negative findings at post mortem}

VHD was an incidental finding in 443 (5.4\%) of all post mortem examinations (Table 2). Excluding those with VHD as any cause of death, $346(4.4 \%)$ had 
purely incidental VHD (Supplementary Table 4). The most common finding was aortic sclerosis although other more significant valve pathologies, including bicuspid aortic valve (BAV), were noted. A pre-mortem diagnosis of VHD (predominantly regurgitant lesions) was unconfirmed at post-mortem in a small number of individuals ( $n=22,0.3 \%$, Table 2 ).

\section{Deaths related to valve procedures}

A minority of deaths ( $n=95,1.2 \%$ of all post-mortems and $14 \%$ of those with any causal or incidental finding of VHD on post-mortem) related to a surgical or interventional valve procedure in the preceding 30 days (Table 3 ). The most frequent were coronary artery bypass grafting with aortic valve replacement (AVR) and isolated AVR ( $n=35$ and $22,5.2 \%$ and $3.3 \%$ of the total VHD population, respectively).

\section{DISCUSSION}

Herein we present the largest reported study examining the clinical correlation between pre- and post-mortem detection of VHD. Whilst our data are derived from the selected cohort of individuals who undergo post mortem, they convincingly demonstrate that pre-mortem clinical information has lowmoderate sensitivity and high specificity for the detection of VHD as a certified cause of death. Since the majority of death certificates are based solely on pre-mortem clinical information, these findings suggest that the mortality burden of VHD is likely to be underestimated at population level. Conversely (and reassuringly from a clinical perspective), the high positive and negative predictive value of pre-mortem clinical information imply high accuracy of death certification at individual patient level.

Our finding of a total VHD prevalence of $8.2 \%$ (326 with VHD as a principal or contributing cause of death and a further 346 as an incidental finding), rising to $10.1 \%$ in those aged 65 years and older, correlates well with previous imaging-based population studies and emphasizes the growing burden of VHD, particularly in the rapidly expanding elderly populations of high income 
countries.[3,13] Although the very high burden of mild VHD observed in a recent echocardiographic study of a related UK-based population [3] was not seen in the present study, detection of mild regurgitant lesions would not be expected at post-mortem examination. The present findings suggest that approximately half of those with VHD detectable at post-mortem die as a direct consequence, whilst the remainder die with, but not as a consequence of, VHD.

Our study also suggests that VHD causing or contributing to death is not identified during life in a small but significant proportion of individuals $(n=142$, $1.7 \%$ of population studied). We found that previously undiagnosed VHD (particularly aortic stenosis) was more common with older age, although undiagnosed infective endocarditis was also common among younger individuals. Aortic stenosis has a long latent asymptomatic phase and was an undiagnosed cause of death in just under $1 \%$ of individuals in our cohort. Aortic valve replacement is safer prior to the development of myocardial fibrosis and heart failure secondary to pressure-overload [14] and earlier diagnosis is likely to improve outcomes. Greater awareness of VHD as a cause of cardiac symptoms in the elderly, combined with a low threshold for echocardiography in individuals with a murmur or higher clinical likelihood of VHD (eg. those in atrial fibrillation), may be appropriate. Infective endocarditis is relatively rare with a prevalence of 3-10 cases per 100,000 person-year, and missed or delayed diagnosis is frequently associated with adverse outcome.[15] Although population-based screening for infective endocarditis would clearly be inappropriate, a low threshold of suspicion for the diagnosis remains vital to improve outcomes.[15]

Previous cohort studies have demonstrated that subjects diagnosed with a bicuspid aortic valve (BAV) in their early 30s have cardiovascular and aortic valve related death rates of $1.5-3 \%$ over $9-15$ years follow-up.[14,15] Extrapolating these outcomes to older BAV subjects is problematic, since accelerated calcification is often observed in the fifth and sixth decades. 
However, in the present study, we demonstrate that there remain a small number of septuagenarians and octogenarians with a BAV who do not undergo valve replacement and die of other causes. These findings would be consistent with an older autopsy study, which demonstrated a BAV which did not contribute to the cause of death in $0.8 \%$ of men and $0.2 \%$ of women aged 65 years and older.[17] Improved understanding of BAV pathophysiology and identification of individuals who appear to be safeguarded from rapid disease progression may facilitate investigation of mechanisms that protect against valve calcification [18] and stimulate efforts to generate disease-modifying therapies for aortic stenosis.

Our study has a number of limitations. The most important is the selected nature of the population who undergo post-mortem examination. While we did not exclude those undergoing consented post-mortems, most autopsies are requested by the Coroner to investigate sudden and unexplained deaths which may increase the proportion with undiagnosed VHD as a cause. A perhaps more representative national population analysis (albeit from a different era) is provided from Iceland, where $30 \%$ of individuals underwent post-mortem examination from 1966-1974 (one third for medicolegal reasons) [17] demonstrating non-rheumatic calcification of a trileaflet aortic valve in $2.5 \%$ (almost identical to the $2.6 \%$ in our study). Moreover, autopsy findings may not necessarily be an appropriate gold standard given that the pathophysiological importance of VHD may be difficult (or impossible) to discern on anatomical examination alone. Valvular regurgitation, for example, usually has a physiological basis and is therefore less likely to be identified at autopsy; individuals with a pre-mortem diagnosis of VHD that was not confirmed at autopsy are likely to fall into this category. Finally, there may be significant inter-individual variation amongst pathologists in the reporting of autopsy findings and their interpretation as a cause of death. This is further complicated by the linear and binary format of the death certificate, which has limited ability to reflect the complexity of interacting, multisystem disease, prevalent in the older populations that bear the highest burden of VHD. 


\section{CONCLUSIONS}

These data demonstrate that clinical information available prior to death is a highly specific (but relatively insensitive) predictor of the cause of death established at autopsy. Although high positive and negative predictive values confirm that death certification is likely to be highly accurate for individual patients, low sensitivity implies that VHD is likely to be an underestimated cause of death at population level. 


\section{ACKNOWLEDGEMENTS}

None

\section{COMPETING INTERESTS}

None

\section{FUNDING}

SC and BDP were supported by the National Institute for Health Research Oxford Biomedical Research Centre. ARH was supported through the National Institute for Health Research Academic Foundation Programme, and $\mathrm{BC}$ by the BHF Centre of Research Excellence, Oxford (British Heart Foundation, grant RE/13/1/30181). The views expressed here are the authors' and not necessarily those of the UK Department of Health.

\section{LICENSE}

The Corresponding Author has the right to grant on behalf of all authors and does grant on behalf of all authors, an exclusive licence (or non exclusive for government employees) on a worldwide basis to the BMJ Publishing Group Ltd and its Licensees to permit this article (if accepted) to be published in HEART editions and any other BMJPGL products to exploit all subsidiary rights. 


\section{REFERENCES}

1 Pagidipati NJ, Gaziano TA. Estimating Deaths From Cardiovascular Disease: A Review of Global Methodologies of Mortality Measurement. Circulation 2013;127:749-56. doi:10.1161/CIRCULATIONAHA.112.128413

2 Coffey S, Williams MJA, Cox B. Letter by Coffey et al regarding article, 'Estimating deaths from cardiovascular disease: a review of global methodologies of mortality measurement'. Circulation 2013;128:e84. doi:10.1161/CIRCULATIONAHA.113.002123

3 D'Arcy JL, Coffey S, Loudon MA, et al. Large-scale community echocardiographic screening reveals a major burden of undiagnosed valvular heart disease in older people: the OxVALVE Population Cohort Study. Eur Heart J 2016; ehw229 [Epub ahead of print]. doi:10.1093/eurheartj/ehw229

4 Coffey S, Cox B, Williams MJA. Lack of progress in valvular heart disease in the pre-transcatheter aortic valve replacement era: increasing deaths and minimal change in mortality rate over the past three decades. Am Heart J 2014;167:562-567.e2. doi:10.1016/j.ahj.2013.12.030

5 d'Arcy JL, Prendergast BD, Chambers JB, et al. Valvular heart disease: the next cardiac epidemic. Heart 2011;97:91-3. doi:10.1136/hrt.2010.205096

6 Nishimura RA, Otto CM, Bonow RO, et al. 2014 AHA/ACC Guideline for the Management of Patients With Valvular Heart Disease: executive summary: a report of the American College of Cardiology/American Heart Association Task Force on Practice Guidelines. Circulation 2014;129:2440-92. doi:10.1161/CIR.0000000000000029

7 Vahanian A, Alfieri O, Andreotti F, et al. Guidelines on the management of valvular heart disease (version 2012): The Joint Task Force on the Management of Valvular Heart Disease of the European Society of Cardiology (ESC) and the European Association for Cardio-Thoracic Surgery (EACTS). Eur Heart J 2012;33:2451-96. doi:10.1093/eurheartj/ehs109

8 Roldan CA, Shively BK, Crawford MH. Value of the cardiovascular physical examination for detecting valvular heart disease in asymptomatic subjects. Am J Cardiol 1996;77:1327-31.

9 Saad R, Yamada AT, Pereira da Rosa FHF, et al. Comparison between clinical and autopsy diagnoses in a cardiology hospital. Heart 2007;93:1414-9. doi:10.1136/hrt.2006.103093

10 Sington JD, Cottrell BJ. Analysis of the sensitivity of death certificates in 440 hospital deaths: a comparison with necropsy findings. J Clin Pathol 2002;55:499-502. 
11 Ministry of Justice. Coroners statistics 2014.

https://www.gov.uk/government/statistics/coroners-statistics-2014 (accessed 29 Nov2016).

12 World Health Organization. International statistical classification of diseases and related health problems. 10th revision, edition 2010. Geneva: : WHO Press 2011.

13 Nkomo VT, Gardin JM, Skelton TN, et al. Burden of valvular heart diseases: a population-based study. Lancet 2006;368:1005-11. doi:10.1016/S0140-6736(06)69208-8

14 Azevedo CF, Nigri M, Higuchi ML, et al. Prognostic significance of myocardial fibrosis quantification by histopathology and magnetic resonance imaging in patients with severe aortic valve disease. J Am Coll Cardiol 2010;56:278-87. doi:10.1016/j.jacc.2009.12.074

15 Cahill TJ, Prendergast BD. Infective endocarditis. Lancet 2016;387:882-93. doi:10.1016/S0140-6736(15)00067-7

16 Tzemos N, Therrien J, Yip J, et al. Outcomes in adults with bicuspid aortic valves. JAMA 2008;300:1317-25. doi:10.1001/jama.300.11.1317

17 Hallgrímsson J, Tulinius $\mathrm{H}$. Chronic non-rheumatic aortic valvular disease: a population study based on autopsies. J Chronic Dis 1979;32:355-63.

18 Harper AR, Nayee S, Topol EJ. Protective alleles and modifier variants in human health and disease. Nat Rev Genet 2015;16:689-701. doi:10.1038/nrg4017 


\section{Tables}

Table 1: Demographics of the study population

\begin{tabular}{|c|c|c|}
\hline & $\begin{array}{l}\text { Women } \\
n=3050\end{array}$ & $\begin{array}{c}\text { Men } \\
n=4829\end{array}$ \\
\hline \multicolumn{3}{|l|}{ No VHD at post-mortem } \\
\hline Deaths, n (\%) & 2722 (89.2\%) & $4485(92.9 \%)$ \\
\hline Age at death, mean (SD) & $72.4(16.6)$ & $66.1(17.4)$ \\
\hline \multicolumn{3}{|l|}{ Any VHD at post-mortem } \\
\hline Deaths, n (\%) & $328(10.8 \%)$ & $344(7.1 \%)$ \\
\hline Age at death, mean (SD) & $77.7(12.0)$ & $73.9(13.4)$ \\
\hline \multicolumn{3}{|l|}{ VHD as principal cause of death } \\
\hline Deaths, n (\%) & $86(2.8 \%)$ & $79(1.6 \%)$ \\
\hline Age at death, mean (SD) & $75.8(13.2)$ & $69.9(16.0)$ \\
\hline \multicolumn{3}{|l|}{$\begin{array}{l}\text { VHD as principal or contributory } \\
\text { cause of death }\end{array}$} \\
\hline Deaths, n (\%) & $162(5.3 \%)$ & $164(3.4 \%)$ \\
\hline Age at death, mean (SD) & $76.1(13.3)$ & $72.4(14.2)$ \\
\hline \multicolumn{3}{|l|}{ VHD as incidental finding } \\
\hline Deaths, n (\%) & $166(5.4 \%)$ & $180(3.7 \%)$ \\
\hline Age at death, mean (SD) & $79.2(10.4)$ & $75.3(12.5)$ \\
\hline
\end{tabular}

Only those with complete demographic data were included $(n=7879)$. Percentages refer to the relevant gender-specific group.

Abbreviations: PM, post-mortem; VHD, valvular heart disease. 
Table 2. Pre- and post-mortem findings.

\begin{tabular}{|c|c|c|c|c|c|}
\hline & $\begin{array}{l}\text { Diagnosed } \\
\text { pre- } \\
\text { mortem }\end{array}$ & $\begin{array}{l}\text { Post- } \\
\text { mortem: } \\
\text { listed as any } \\
\text { cause of } \\
\text { death }\end{array}$ & $\begin{array}{l}\text { Post- } \\
\text { mortem: } \\
\text { Incidental } \\
\text { finding }\end{array}$ & $\begin{array}{l}\text { Missed pre- } \\
\text { mortem } \\
\text { (false } \\
\text { negatives) } \\
\end{array}$ & $\begin{array}{l}\text { Diagnosed } \\
\text { pre- } \\
\text { mortem, but } \\
\text { not } \\
\text { confirmed } \\
\text { at autopsy }\end{array}$ \\
\hline Any VHD & 372 (4.5\%) & $326(4.0 \%)$ & $443(5.3 \%)$ & $142(1.7 \%)$ & $22(0.3 \%)$ \\
\hline Aortic stenosis & 89 (1.1\%) & $119(1.5 \%)$ & $91(1.1 \%)$ & 75 (0.9\%) & $4(0.0 \%)$ \\
\hline Aortic regurgitation & $17(0.2 \%)$ & $2(0.0 \%)$ & $4(0.1 \%)$ & $1(0.0 \%)$ & $2(0.0 \%)$ \\
\hline Endocarditis & $13(0.2 \%)$ & $27(0.3 \%)$ & $9(0.1 \%)$ & $16(0.2 \%)$ & $0(0.0 \%)$ \\
\hline $\begin{array}{l}\text { Mitral valve } \\
\text { disease }\end{array}$ & $63(0.8 \%)$ & $17(0.2 \%)$ & 87 (1.1\%) & $9(0.1 \%)$ & $13(0.2 \%)$ \\
\hline $\begin{array}{l}\text { Tricuspid } \\
\text { regurgitation }\end{array}$ & $16(0.2 \%)$ & $3(0.0 \%)$ & $23(0.3 \%)$ & $2(0.0 \%)$ & $4(0.0 \%)$ \\
\hline $\begin{array}{l}\text { Rheumatic heart } \\
\text { disease }\end{array}$ & $12(0.2 \%)$ & $20(0.2 \%)$ & $37(0.5 \%)$ & $15(0.2 \%)$ & $0(0.0 \%)$ \\
\hline $\begin{array}{l}\text { Valve } \\
\text { repair/replacement }\end{array}$ & $184(2.2 \%)$ & $117(1.4 \%)$ & $67(0.8 \%)$ & $0(0 \%)$ & $0(0.0 \%)$ \\
\hline Miscellaneous & $9(0.1 \%)$ & $26(0.3 \%)$ & $24(0.3 \%)$ & $21(0.3 \%)$ & $0(0.0 \%)$ \\
\hline $\begin{array}{l}\text { Mitral annular } \\
\text { calcification }\end{array}$ & $1(0.0 \%)$ & $5(0.1 \%)$ & 90 (1.1\%) & $5(0.1 \%)$ & $0(0.0 \%)$ \\
\hline Aortic sclerosis & $5(0.1 \%)$ & $3(0.0 \%)$ & $108(1.3 \%)$ & $3(0.0 \%)$ & $1(0.0 \%)$ \\
\hline $\begin{array}{l}\text { Bicuspid aortic } \\
\text { valve }\end{array}$ & $8(0.1 \%)$ & $12(0.2 \%)$ & $24(0.3 \%)$ & $8(0.1 \%)$ & $1(0.0 \%)$ \\
\hline
\end{tabular}

Those without complete demographic data were included ( $\mathrm{n}=8198$ for all percentages). "Missed pre-

mortem" indicates where VHD had not been diagnosed pre-mortem but was listed as a cause of death following autopsy. Individuals could have more than one form of VHD. Incidental findings include individuals with other forms of VHD as any cause of death. Abbreviation: VHD, valvular heart disease. 
Table 3: Medical procedures performed within 30 days of death in individuals with valvular heart disease at post-mortem

\begin{tabular}{lc}
\hline Procedure & $\mathbf{n}(\%)$ \\
\hline Aortic valve replacement and CABG & $35(36.8 \%)$ \\
Aortic valve replacement & $22(23.2 \%)$ \\
Other non-cardiac surgery & $8(8.4 \%)$ \\
Other cardiac surgery & $6(6.3 \%)$ \\
CABG & $4(4.2 \%)$ \\
CABG and mitral valve repair & $4(4.2 \%)$ \\
CABG and mitral valve replacement & $4(4.2 \%)$ \\
Transcatheter aortic valve implantation & $4(4.2 \%)$ \\
Aortic valve replacement and mitral valve & $3(3.2 \%)$ \\
repair/replacement & $2(2.1 \%)$ \\
Mitral valve repair & $2(2.1 \%)$ \\
Mitral valve replacement & $1(1.1 \%)$ \\
\hline Tricuspid valve repair & $95(100 \%)$ \\
\hline Total
\end{tabular}

Abbreviations: CABG, coronary artery bypass grafting 


\section{FIGURES}

Figure 1: Prevalence of valvular heart disease as a cause of death (stratified by age at death)

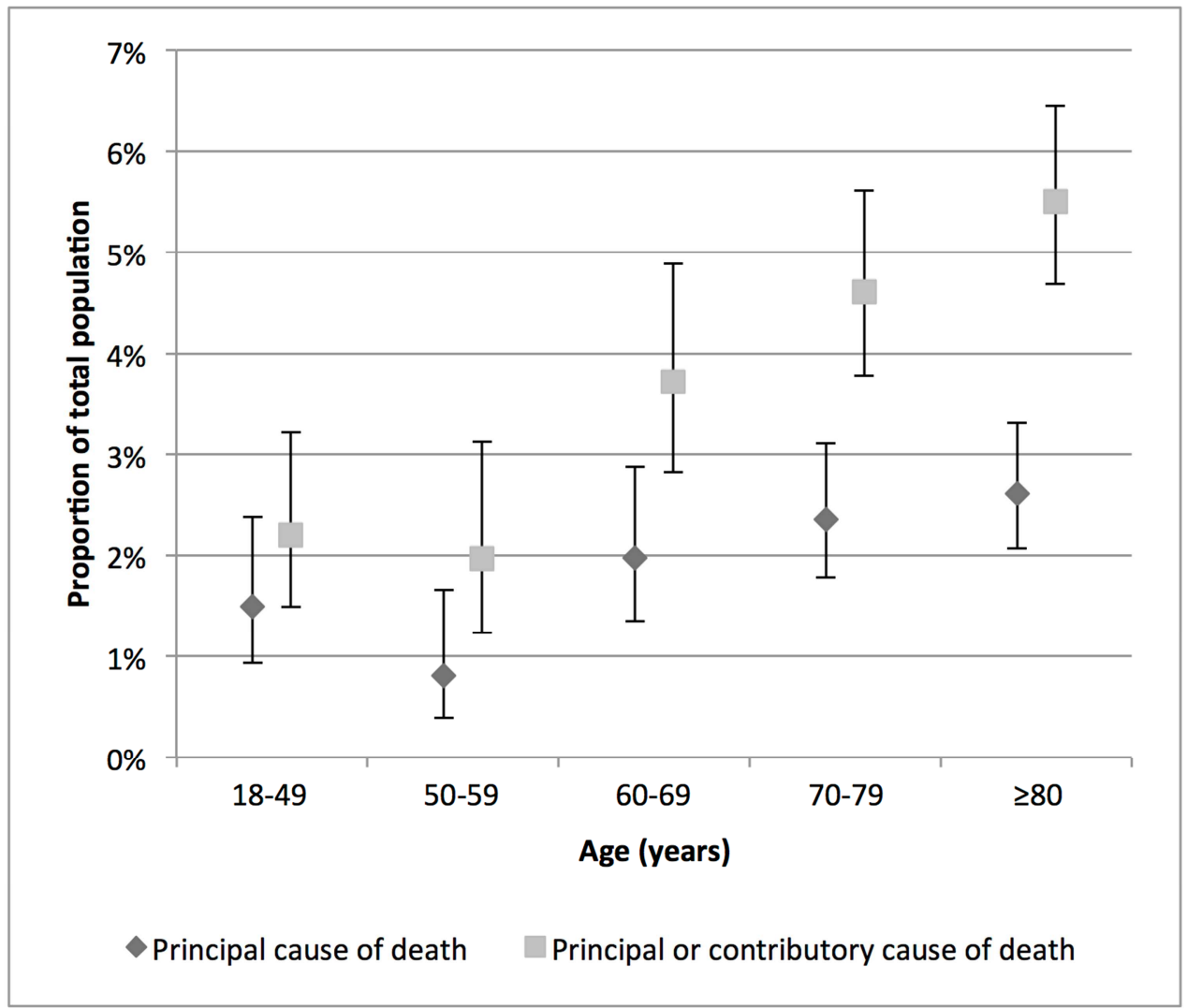

Error bars represent 95\% confidence intervals 
Figure 2. Prevalence of conditions newly diagnosed at post-mortem and listed as a principal or contributory cause of death (stratified according to age at death): (A) valvular heart disease (B) aortic stenosis (C) endocarditis

A. Any valvular heart disease

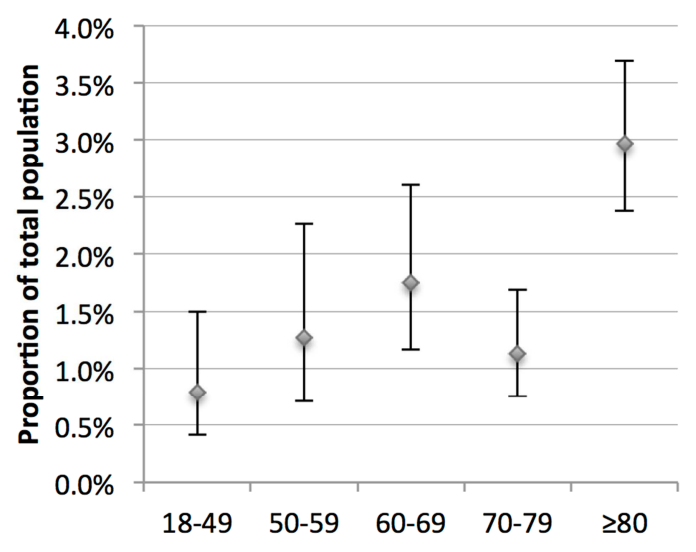

B. Aortic stenosis

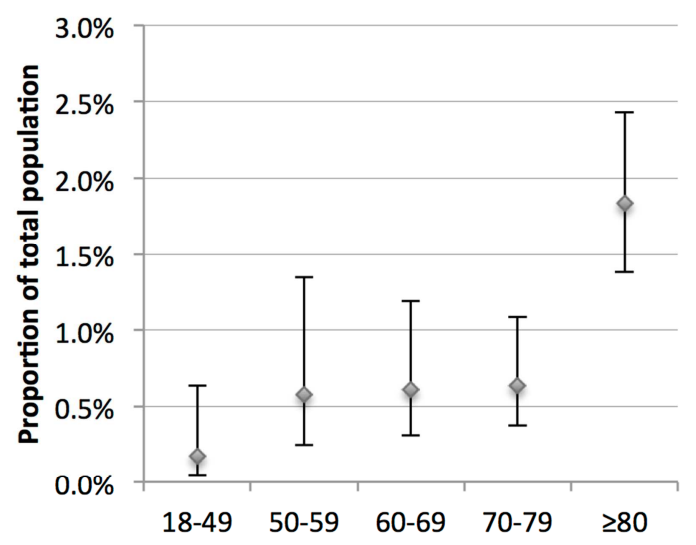

C. Endocarditis

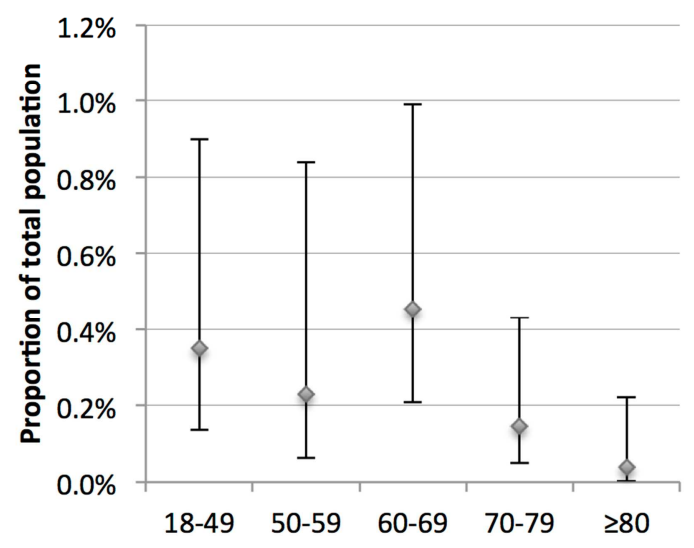

Error bars represent 95\% confidence intervals. 